\title{
Failure mechanisms and ground support applications at Coleman mine, Sudbury Basin
}

\author{
D Landry Vale Canada Ltd., Canada \\ E Reimer Vale Canada Ltd., Canada
}

\begin{abstract}
The primary ground control challenges at Coleman mine in the Sudbury Basin are those associated with high stress conditions. The combination of a competent and strong host rock, a relatively weak ore unit and a high horizontal stress regime, produces a wide variety of ground conditions. Depending on mining geometry, observed ground conditions range from highly confined and high stress, to yielded and unconfined. Rockbursting and falls-of-ground have been a significant challenge at Coleman; however, recent design improvements, mining strategies, and ground support practices have significantly reduced incidences and led to improved mining efficiencies. These improvements have strongly relied on seismic monitoring which gives valuable insight to where rock failure is occurring.
\end{abstract}

This paper will highlight conditions observed and ground support strategies utilised at Coleman mine. The interaction between geology, seismicity, mine design, ground support and field observations will be discussed.

Keywords: sill pillar, ground support, seismicity

\section{Introduction}

Coleman mine is located on the north range of the Sudbury Basin and currently produces over 1 Mtpa of nickel-copper-PGE ore. The mine has a long history (roughly 50 years) and the active orebodies have been operating since the early 1990s. Two narrow vein footwall copper and two massive contact nickel deposits are currently being mined between 1,000 and 1,800 $\mathrm{m}$ below surface (Figure 1).

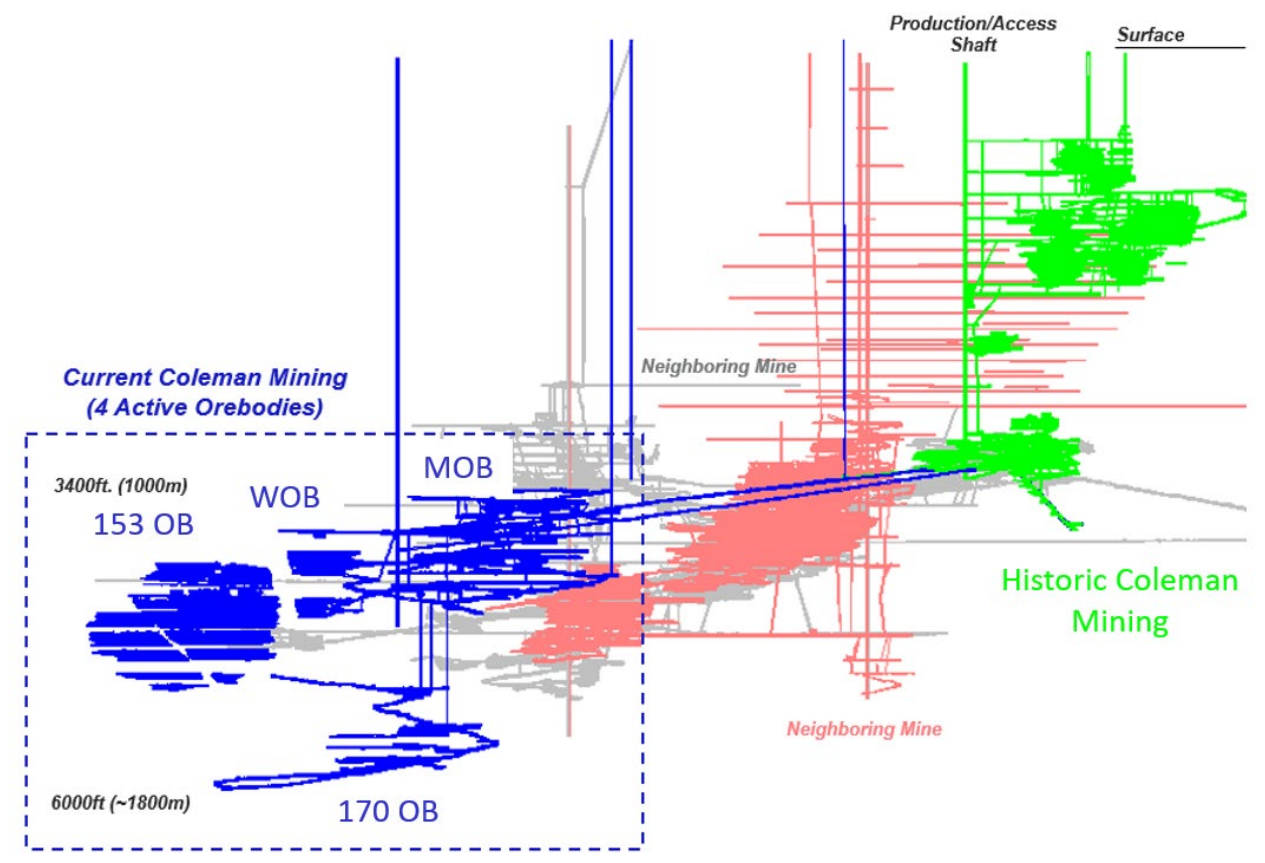

Figure 1 Long view of Coleman mine and adjacent excavations looking north. Blue excavations: active Coleman orebodies; green: historic Coleman mining; pink/grey: neighbouring mines 
The primary mining methods employed are narrow vein cut-and-fill (NVCF), post-pillar cut-and-fill (PPCF), and blasthole open stoping.

The orebodies are hosted in granite gneiss and granite breccia (Sudbury breccia) shown in Figure 2 (density $\sim 2,500 \mathrm{~kg} / \mathrm{m}^{3}$ and unconfined compressive strength $>200 \mathrm{MPa}$ ). Pyrrhotite, chalcopyrite and pentlandite account for the bulk of the sulphide ore (density $\sim 4,000 \mathrm{~kg} / \mathrm{m}^{3}$ and UCS $\sim 100 \mathrm{MPa}$ ).

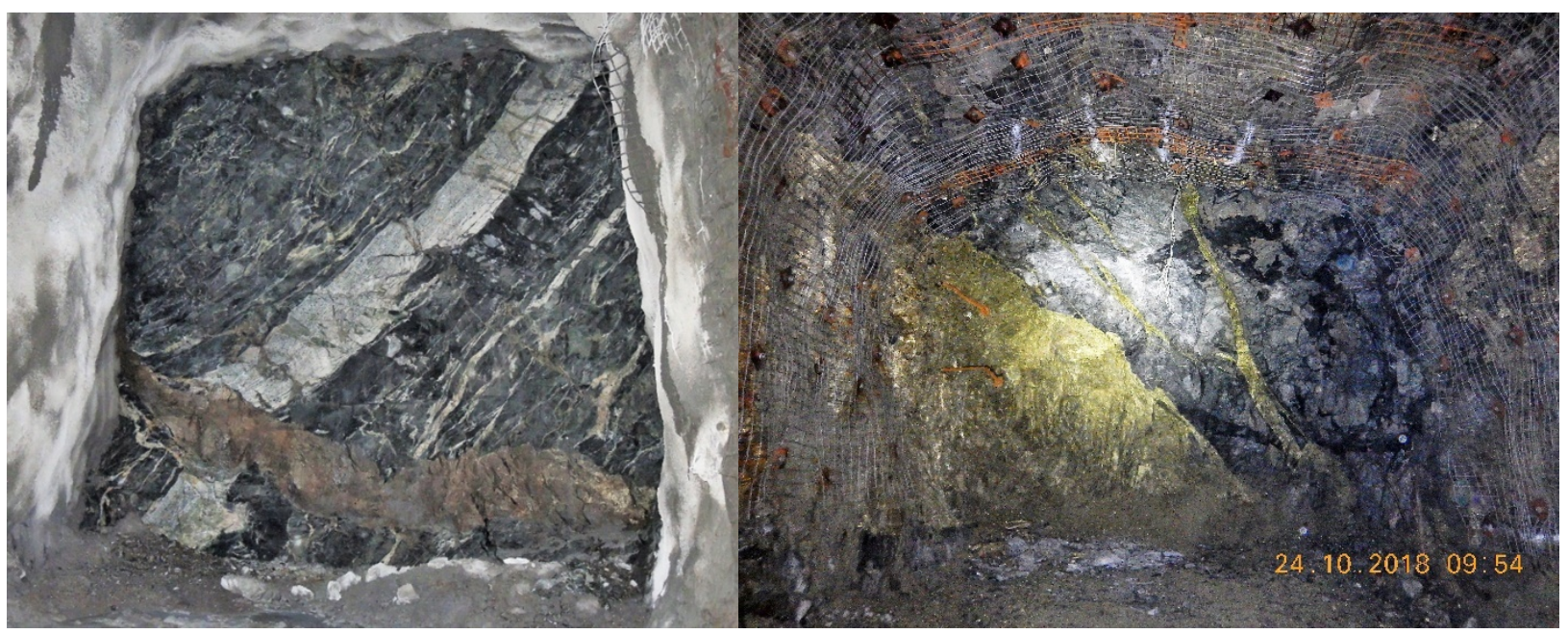

(a)

(b)

Figure 2 Production faces at Coleman. (a) Main orebody drill sill development under backfill with in-cycle shotcrete. Face showing flat lying inclusion sulphide and granite gneiss host; (b) 153 orebody hanging wall overhand narrow vein cut-and-fill heading. Face showing solid massive sulphide hosted in Sudbury breccia

The host rock is very competent and stable during regular development and stoping with only some areas of highly jointed and low-quality rock. However, the granitic host can store energy and is prone to rockbursting when loaded. Conditions in the ore varies but it is generally weak and less competent than the host. In high stress conditions, the ore deforms easily and dilates, giving further degrees of freedom and causes the stiff host to be even more burst-prone. Since the ore is denser and is weaker than the host, it is more of a ground control concern from a gravity standpoint. Similar ground conditions have been documented at neighbouring mines by Simser (2006).

The four active orebodies include the main orebody (MOB), West (WOB), 153 and 170. All orebodies were initially designed with sill pillars, to facilitate multiple mining horizons. The various sills are all currently in different stages from a loading perspective (loading, yielding or yielded); making sill management challenging.

\subsection{Main and West orebodies}

The MOB and WOB are massive contact nickel bearing deposits (Lightfoot 2017) and are hosted in primarily granite gneiss. The $\mathrm{MOB}$ strikes east-west over approximately $350 \mathrm{~m}$ and dips south at $50^{\circ}$ to $60^{\circ}$. Ore thickness averages about $60 \mathrm{~m}$. The WOB is a small pod located approximately $200 \mathrm{~m}$ to the west of the MOB. The central areas of the $\mathrm{MOB} / \mathrm{WOB}$ are composed of nickel sulphide stringers with inclusions of granite gneiss, while the eastern portion of the orebody is massive sulphide with sharp regular footwall and hanging wall contacts. Both the $\mathrm{MOB}$ and $\mathrm{WOB}$ are striking perpendicular to the horizontal principal stress direction.

The MOB was initially mined by Falconbridge (now Glencore) above the 3400 level (due to various mining claims). On the Coleman side, three flat horizons were established below 3400 level. The first sill was initially $120 \mathrm{~m}$ thick and the two subsequent sills were designed to be $60 \mathrm{~m}$. Mining was completed bottom up and mined using PPCF for the first 10 to 15 years of operation (Figure 3). 


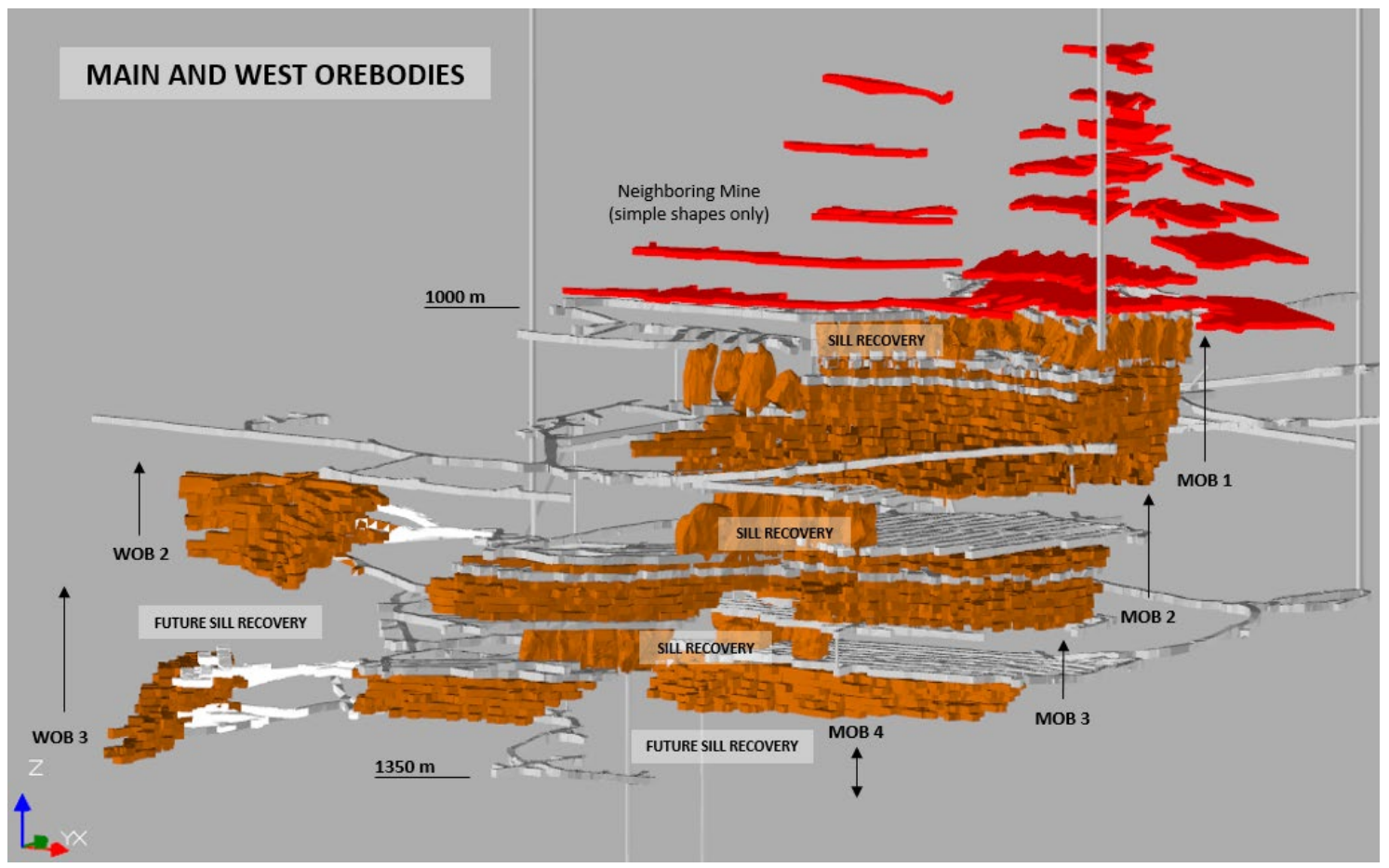

Figure 3 Isometric long view looking north of the Main Orebody (MOB) and West Orebody (WOB). The ore on the east (right) of the MOB is wide and the sills have relaxed, while on the west (left) the ore is thin, and the sills are highly stressed

In PPCF, cuts are mined successively following a bottom up sequence and the post-pillars are stacked on top of each other. Cuts are $5.5 \mathrm{~m}$ high and mining is completed with two-boom jumbos and MacLean bolters. Ground support in early mining consisted of $2.4 \mathrm{~m}$ long mechanical bolts in the back and walls with \#6-gauge welded wire mesh (WWM).

The rockburst record in the $\mathrm{MOB}$ shows that sill cut mining was the primary ground control challenge early on (post-pillar bursts in virgin ground). This was mitigated by identifying and supporting high risk post-pillars. As mining progressed, arched yield zones formed above the back of the large cuts (as per design) and mining was completed in a stress shadowed state.

Within the last 10 years, the mine proactively converted the MOB sills to open stoping due to the anticipation of difficulty in managing back stability due to a lack of confinement in wide areas, and the anticipation of high stress conditions in the thinner areas. The stope sequencing strategy is to retreat stopes from the core of the orebody on single horizons to the abutments to avoid mining towards a diminishing pillar. The ground control focus is to maintain confinement in the squat yielded sills; hence, tight control on concurrent stoping and filling to ensure gravity issues are minimised.

\subsection{3 and 170 orebodies}

The 153 and 170 orebodies (Figure 4) are footwall copper deposits (Lightfoot 2017) and are hosted in primarily Sudbury breccia and granite gneiss. The copper orebodies are roughly $300 \mathrm{~m}$ further in the footwall of the Sudbury Igneous Complex relative to the MOB. The 153 strikes east-west and is more regular than the 170 , in which the veins are much more erratic in strike, dip and thickness. The veins dip from $0^{\circ}$ to $70^{\circ}$ and sometimes roll back up-dip). The individual ore veins are very irregular in width, ranging from centimetres to tens of metres. The 153 strikes perpendicular to the major principal stress and in the 170 Orebody, some veins are perpendicular while some are parallel to the principal stress. 


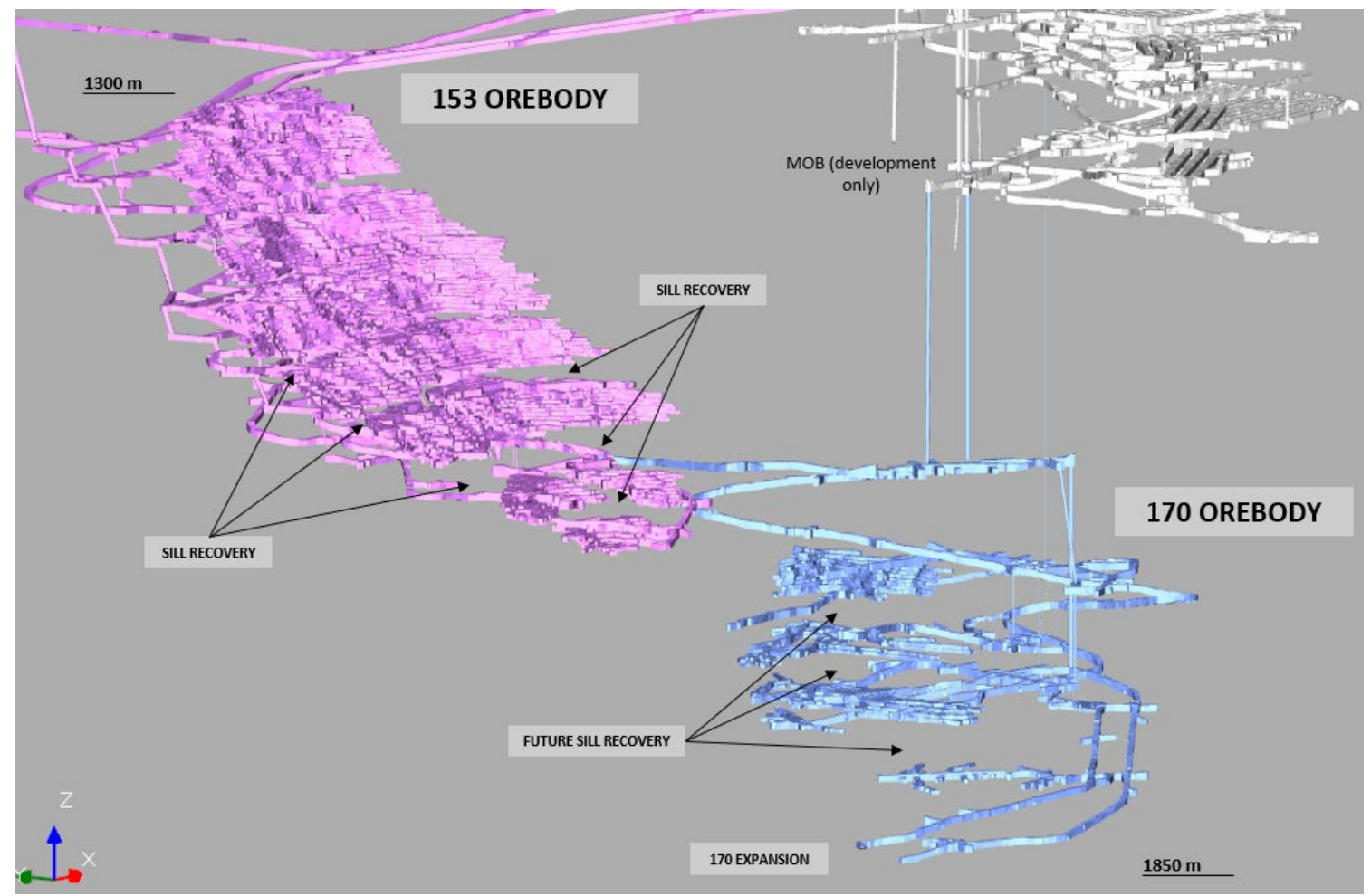

Figure 4 Isometric long view of the 153 and 170 orebodies (not to scale)

In the copper orebodies, the base case mining plan uses overhand NVCF. Main levels are established on $35 \mathrm{~m}$ intervals and the sills are divided into $2.7 \mathrm{~m}$ high cuts to facilitate mining selectivity. Drift rounds are drilled with one-boom jumbos and primary ground support installed with handheld equipment (jackleg and stoper). Ground support in early mining consisted of $2.4 \mathrm{~m}$ long mechanical bolts with standard WWM in the back and shoulders. Where ore is too wide for a single pass, drift-and-fill is utilised (overhand and underhand).

As sill pillar geometries have diminished, mining plans have evolved in recent years to manage the high stress sill conditions. Underhand NVCF with gabion sill mats, longhole stoping, regional de-stressing and the 'double-cut' method is utilised as mitigating strategies (Townend \& Sampson-Forsythe 2014).

There are currently four sill pillars being mined in the 153 and two in 170. A mine expansion is currently ongoing in the lower portion of the 170; the deepest mining level will be $1,850 \mathrm{~m}$ depth.

\subsection{Seismic monitoring}

At Coleman, the primary means utilised to monitor the rock mass response to mining is through seismic monitoring, as well as, regular and well documented underground observations.

The ESG Solutions seismic system at Coleman consists of three individual sensor arrays (one per orebody) of uniaxial and triaxial accelerometers and geophones. Location accuracy and sensitivity varies between the arrays due to geographical complexity, overall extraction and age of the systems themselves. In general, events are located with an error of less than $15 \mathrm{~m}$ and as accurate as $3 \mathrm{~m}$ in some areas.

The 170 orebody array was commissioned in 2012 and is the most accurate of the three arrays. The sensor spacing is tighter and there is a much lower overall extraction, leading to less ray path issues (more of the sensors record the undisturbed seismic wave).

Figure 5 illustrates the usefulness of accurate source locations; five months of seismicity showing a second cut being mined. The seismicity tracks very well with mining and it can be observed that more intense seismicity occurred at the beginning and end of the heading. The response was verified through underground observations; the vein drastically narrowed near the end of the heading and resulted in a stronger seismic response and rockbursting. 


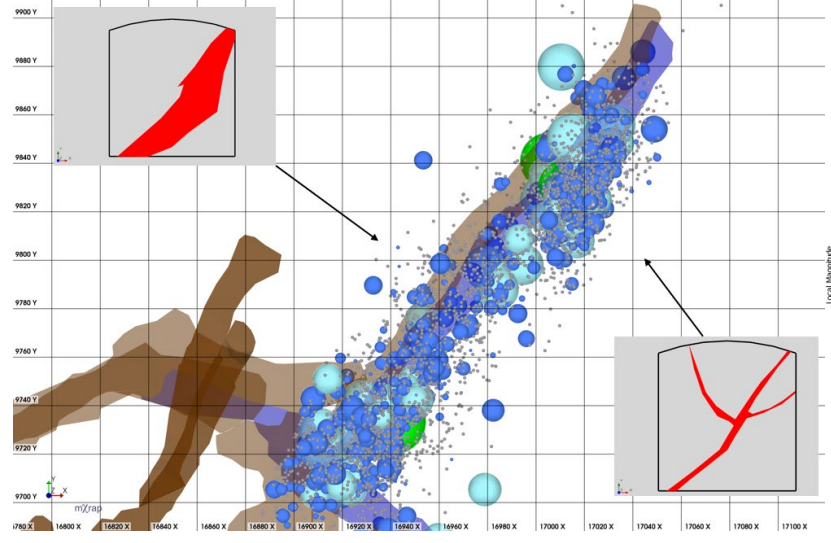

(a)

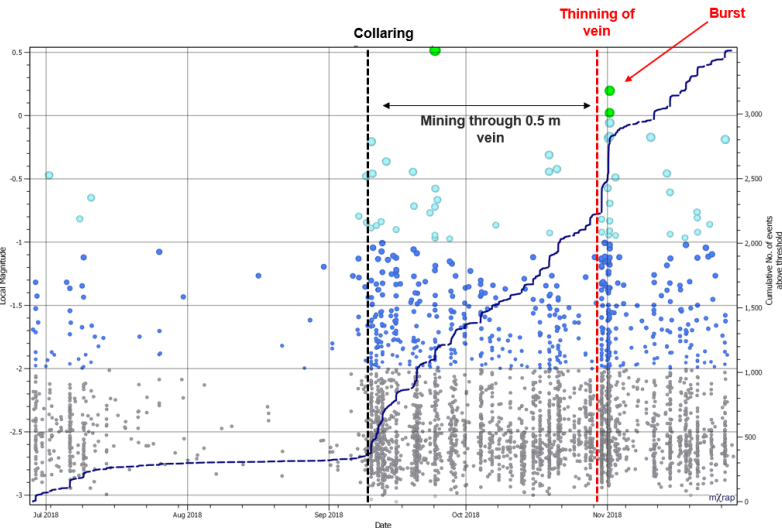

(b)

Figure 5 (a) Plan view showing seismicity tracking a narrow vein cut-and-fill heading and confirming variations given changing ore vein characteristics (mapped faces shown); (b) Magnitude-time $(y-x)$ relation using seismic data from left. Roughly five months of data showing quiet period before mining, collaring and, the sudden increase in seismicity at the beginning of November which resulted in a rockburst

\section{Rock mass failure mechanisms and ground control strategies}

A primary function of the ground control program involves understanding the rock mass response to mining and ensuring designs are effective at managing the given response where ground support is generally the last line of defence.

\subsection{Evolution of ground support}

Initially, the primary ground support systems employed consisted of resin-grouted rebar in permanent excavations and mechanically anchored rockbolts in temporary stoping areas. Systems varied slightly depending on conditions, with split set bolts as alternative wall support, and shotcrete and cable bolts being secondary support elements.

Within the last 10 years, as the 153 Orebody and MOB have matured, a significant evolution has been required to accommodate the change in ground conditions. The most notable changes in ground support practice has been, discontinuing the use of mechanical bolts, frequent use of dynamic support systems, support in underhand mining (inflatables, shotcrete and gabion sill mats), and the introduction of boom style bolters.

\subsection{Control of primary failure mechanisms}

Langevin \& Wilson (2013) held that to design ground control strategies effectively, it is important to understand the key rock mass failure mechanisms. Keeping with this important design approach, the following sections will describe two important observed failure mechanisms and discuss the ground control strategies in place to mitigate them.

\subsubsection{Stress fracturing}

A method to confirm stress variations in mining areas is through observations of the fracture depth around openings. Fracture depth is difficult to measure in regular waste development; however, cut-and-fill mining provides an excellent opportunity to observe the depth of fracturing in the back, floor and walls of previously mined areas. From a ground support design standpoint, documentation of observed fracturing is important as it relates to tendon length. Figure 6 shows the concept of depth of fracturing along with a confirmed underground observation. 


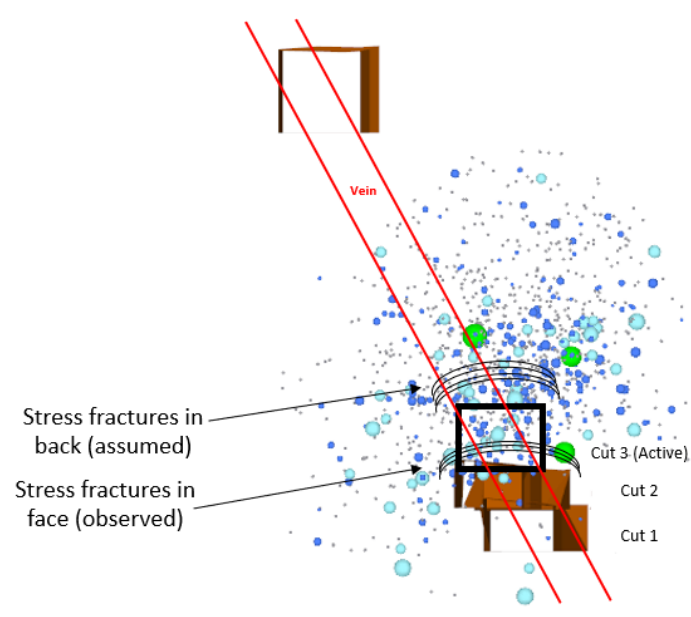

(a)

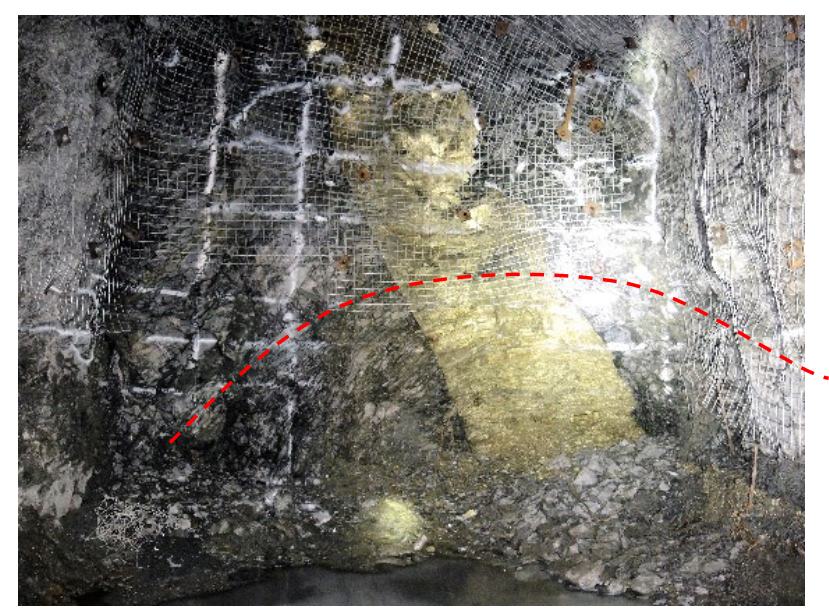

(b)

Figure 6 (a) Section view showing mining geometry, interpretation of failure mechanism and corresponding seismicity for one week while mining through this section; (b) Underground photo of the cut 3 heading (170-5440-3S) showing an observed fracturing that occurred while mining the cut below

In NVCF stopes, rock fracturing is highly dependent on the mining geometry (mined below, beside or above), characteristics of the ore veins and direction of the drive relative to the principal stress. For example, a flat dipping overhand heading is stress shadowed on the wall that follows the previous cut (downbreak) and potentially stressed on the opposing shoulder. Considering ore vein characteristics, a wide and rich ore vein generally allows for more dilation, deeper fracturing, and 'softer' seismic response (relatively more small events versus large events). Response while mining thinner veins is observed to be stiffer and generally produces single large events versus many small microseismic events. In addition, the high variation in rock mass properties has proven to increase strainburst potential and in general, damage is observed in the host rock adjacent to the massive sulphide veins. In many cases, strainbursts were triggered when the ore veins abruptly change orientation, or when they are divided.

Field observations show that seismicity is elevated by drilling and adding water to the rock face (Figure 7). This mechanism is difficult to manage, and worker awareness is an invaluable control; recognising variations in vein geometry and understanding potential outcomes. As an additional precaution, faces are not drilled with handled drills (jacklegs). A strategy to reduce worker exposure to high stress ground in narrow vein headings is using low profile mechanical bolting units. The narrow vein boom-bolter (Fletcher) is currently in use and operates in $3.3 \times 3.3 \mathrm{~m}$ openings (Figure 7).

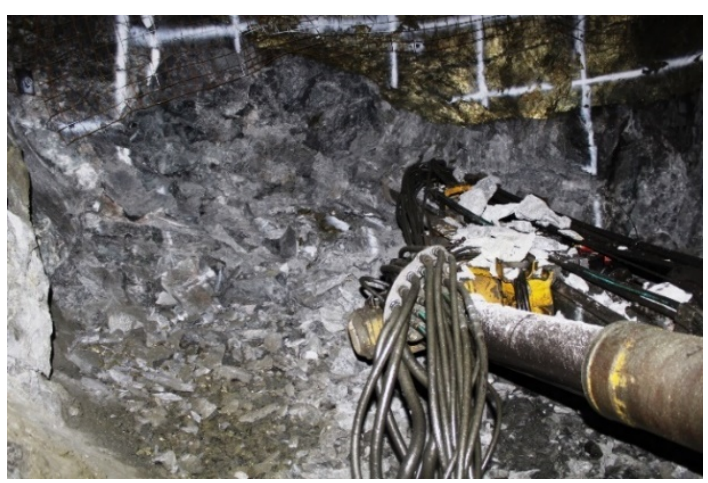

(a)

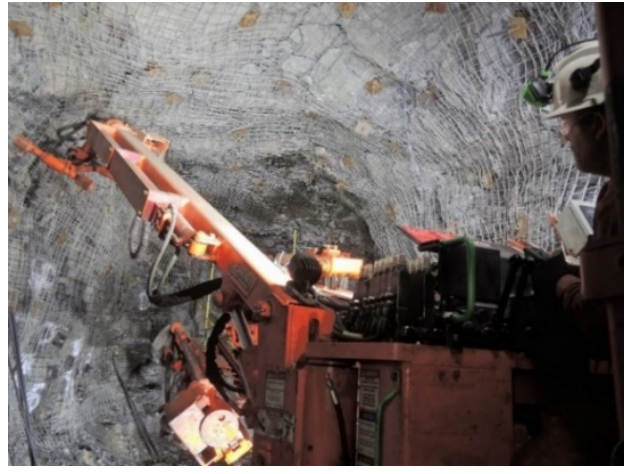

(b)

Figure 7 (a) Underground photo of a strainburst that occurred while drilling with a jumbo. In this situation the vein orientation changed drastically resulting in a stress concentration in the host rock; (b) Narrow vein boom-bolter in operation in a $3.3 \times 3.3 \mathrm{~m}$ heading. The introduction of these units means a reduction in worker exposure (versus handheld bolting) 
Due to equipment limitations, the Fletcher units install only $1.8 \mathrm{~m}$ long inflatables and split set bolts. The limited bolt length also limits the maximum allowable drift span to $5.5 \mathrm{~m}$ (one-third drift span rule-of-thumb) which is an inherent benefit from a ground control perspective.

Ground support strategies, in NVCF areas are site-specific and are highly dependent and geometry and vein characteristics. Observations show that standard back support (resin-grouted rebar and mesh) do not perform well in seismically active ground. Rebar are prone break at the threads and screen is torn at the plate. In areas identified, dynamic bolts (resin-grouted stretch based) with \#0-gauge mesh straps are installed in-cycle. High stress walls are supported to the floor and to the face.

NVCF mining is successfully occurring at $1,800 \mathrm{~m}$ below surface and significant focus has been placed on identifying areas of potential high stress and designing accordingly. For example, ensuring headings remain in the partial stress shadow of the previously mined cut or pass - referred to as 'following downbreak'. A reduction in minor strainbursts has been observed by following this practice. In flat lying veins, this means drift-and-filling from the downbreak to the footwall contact in multiple passes (not the mine planning preference due to ore variability). Internal waste pillars between narrow vein headings also generate seismicity and require specific attention (see case history 1 ).

In waste development, stress driven fracturing is prevalent in the back due to the high horizontal stress and brittle rock. It is observed that stress driven overbreak becomes a concern (in virgin waste development) below $1,500 \mathrm{~m}$ depths. Work is ongoing to quantify the variation in rock fracturing in various areas of the mine.

Strainbursting in the back while installing ground support in waste development has become a significant concern and hazard for bolter operators. As a result, the mines development boom-bolter is made available for site-specific areas that become seismically active (Figure 8). Like the narrow vein units, the mechanised bolter is only outfitted to install $2.4 \mathrm{~m}$ inflatables and split set bolts. Since resin-grouted support is a general standard in long-term development for corrosion resistance, a second pass of support generally required when the boom-bolter is called in. Work is ongoing to advance the use of bulk-resin and associated bolting systems.

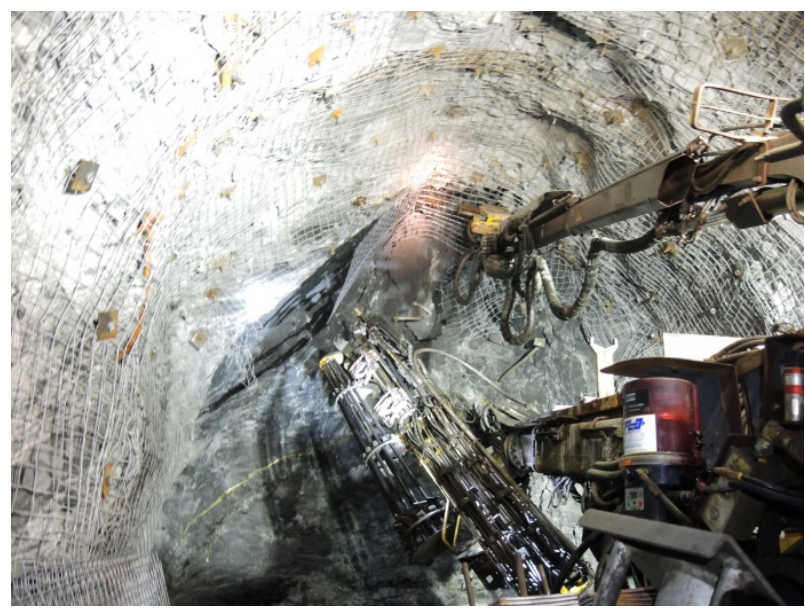

(a)

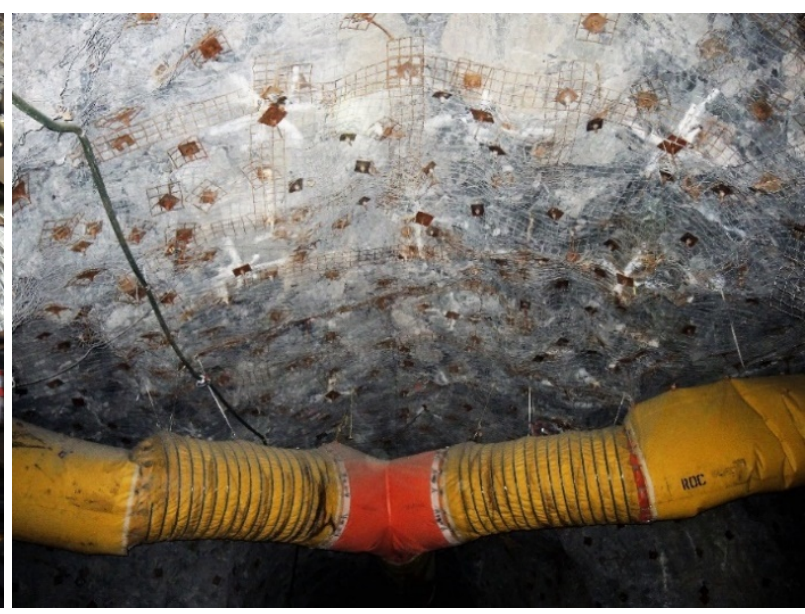

(b)

Figure 8 (a) Development boom-bolter in operation in a high stress development heading; (b) Underground photo showing ground condition encountered on 5950 level (notable rock bulking). The four-way intersection was seismically active while excavating. Primary back support consisted of $2.4 \mathrm{~m}$ resin-grouted dynamic bolts supplemented with $3.6 \mathrm{~m}$ yielding inflatables and straps in-cycle. Once excavated $5.5 \mathrm{~m}$ twin plated cable bolts were installed

In most of the waste development (level, ramp, access etc.), traditional resin-grouted rebar bolts have been substituted with dynamic bolts (resin-grouted stretch based) as primary back support. The mine-wide ground support change is necessitated by the high stress condition at the leading-edge of screen and the freshly 
blasted round, and the recent need to rehabilitate historic areas previously supported with grouted rebar (observed failure due to repeated seismic loading). Walls are supported with $1.8 \mathrm{~m}$ resin-grouted rebar as stress related issues are rarely observed in waste development. Prior to drilling and loading, all development faces are supported with $46 \mathrm{~mm}$ diameter, $2 \mathrm{~m}$ long friction bolts and screen using the jumbo drill. Depending on local conditions, in-cycle support enhancements are sometimes required. Typically, \#0-gauge squares are installed behind the bolt plate to provide further surface support at the connection between the tendons and the mesh. If fracturing and seismicity is significant, a second pass of $3.6 \mathrm{~m}$ long yielding inflatables and straps are installed in-cycle to ensure the fractured zone in the back is adequately pinned to solid prior to advancing the heading. Plated $5.5 \mathrm{~m}$ long twin cable bolts are installed in the back of intersections with spans greater than $7.5 \mathrm{~m}$; onsite-specific patterns. An example of this support system is seen in Figure 8.

\subsubsection{Sill pillar failure}

At Coleman, the primary ground control challenge is managing conditions encountered in sill pillar mining. The geometry of the sills varies from a width, height and dip perspective; however, the failure mechanism is generally the same; as pillar geometry is diminished, the pillar core loads, begins to fail and yields, with the load (stress) being shed to the abutment. The challenge is managing the seismicity generated from the loading and yielding cycle. Once a pillar has yielded, gravity takes over and conditions are slightly more manageable.

Figure 9 shows how the failure mechanism has been verified using three practical methods: non-linear numerical model, seismic monitoring data, and field observations. It can be seen in the figure that all three loading stages are well matched by all three verification methods.

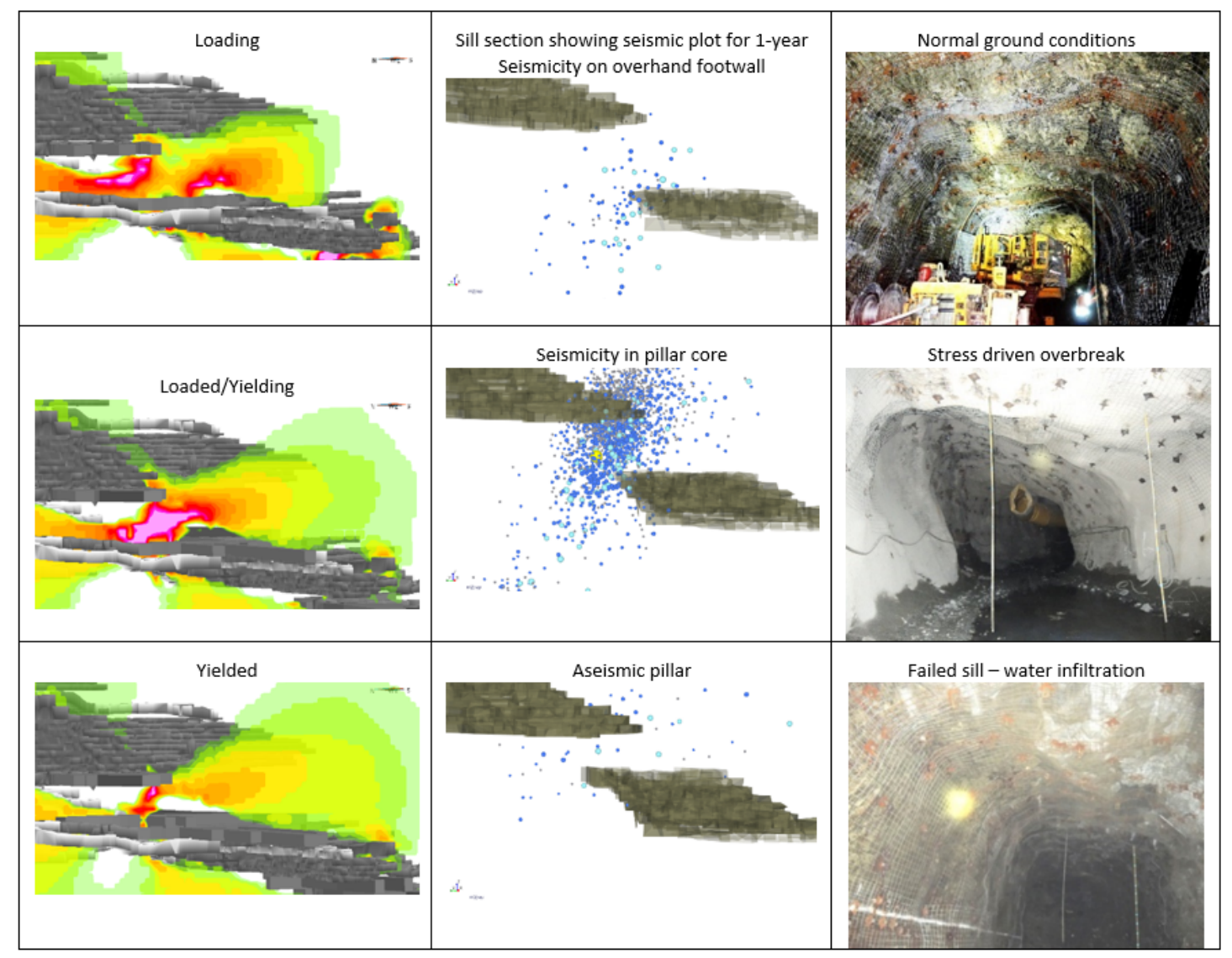

Figure 9 Images showing justification for assumed sill pillar loading and yielding failure mechanisms. Non-linear stress model (Itasca Consulting Canada Inc. 2017) showing deviatoric stress (increasing stress in darker colour), recorded seismicity for a one-year period while in the presumed loading stage, and corresponding underground observations during the presumed loading stage. All data from 153-4810 block 2 sill 
Sill loading depends primarily on geometry and mining sequence; however, the variations in the ore veins (thickness and dip) also play an important role. In the lower portion of the 153, the ore is flat lying, and stress concentrates on the footwall side of the overhand cuts and hanging wall side of the underhand cuts; the pillar core. The benefit to being shallow dipping is that most of the headings are not exposed to high stress, as they are in a stress shadow (gravity or seismic shaking is the main concern). In addition, the ore veins are thick (10 $\mathrm{m}$ in some cases) and soften the high stress condition by early fracturing and dilation. The veins in the 170 are narrower than the 153 , orientations are much more variable and future sill loading is anticipated to be much more complex. Sill recovery is being planned far in advance to ensure many options remain open for as long as possible.

There are currently three sills being mined in the MOB. In the heart of the MOB, the orebody is roughly $300 \mathrm{~m}$ in length and width, and observations have shown that the two large sills (M3 and T5) have yielded $(\mathrm{W}: \mathrm{H} \sim 0.4)$. Seismicity is only observed when mining stopes on the abutments and the ground is showing signs of relaxation. In these areas, gravity and water (corrosion) is the primary ground control concern. Ground control strategies include: the large-scale use of long cable bolts $(5.5 \mathrm{~m})$ plated with rigid surface support (straps), good documentation of the 'state of support' to track ground support condition, and tight control on stope and fill sequencing. Where the ore narrows on the east abutment, high stress and seismicity are observed due to the confined and slender sills (W:H 1.2). In these blocks, seismicity is observed and is driven by stope blasting. Stope are mined in a pillarless sequence and are retreating to the abutment. Re-entry is employed on a regular basis following stope blasts to keep workers out of seismically active areas. Case study 2 shows an example of seismicity observed in a regional pillar of the MOB and ground support performance during a large seismic event.

The preferred strategy for recovering cut-and-fill sills, is to convert to bulk stoping prior to the pillar being loaded. The challenge in the 153 and 170 orebodies is the veins are for the most part flat lying (average of $30^{\circ}$ ), and thus bulk stoping is not well suited. In sills where the veins are too flat for open stopes, the strategy remains to reduce worker exposure through improvements to the overall block design, sequencing and regional de-stressing. Local sequencing plays a significant role (i.e. retreating from the hanging wall to delay mining in high stress). High stress areas in sill pillars are never mined using conventional techniques (i.e. muck pile with jackleg/stopers). Drift size is increased to allow for more mechanised equipment (boom-bolters and two-boom jumbos) and safer installation of ground support, regional de-stress curtains are drilled/blasted and have been successful (Townend \& Sampson-Forsythe 2014), and seismic monitoring is prioritised. Figure 10 shows a general section of the flat dipping sill pillar arrangement with interpreted and observed failure mechanisms. Figure 11 shows examples of underground observation in the given conditions and associated ground support systems.

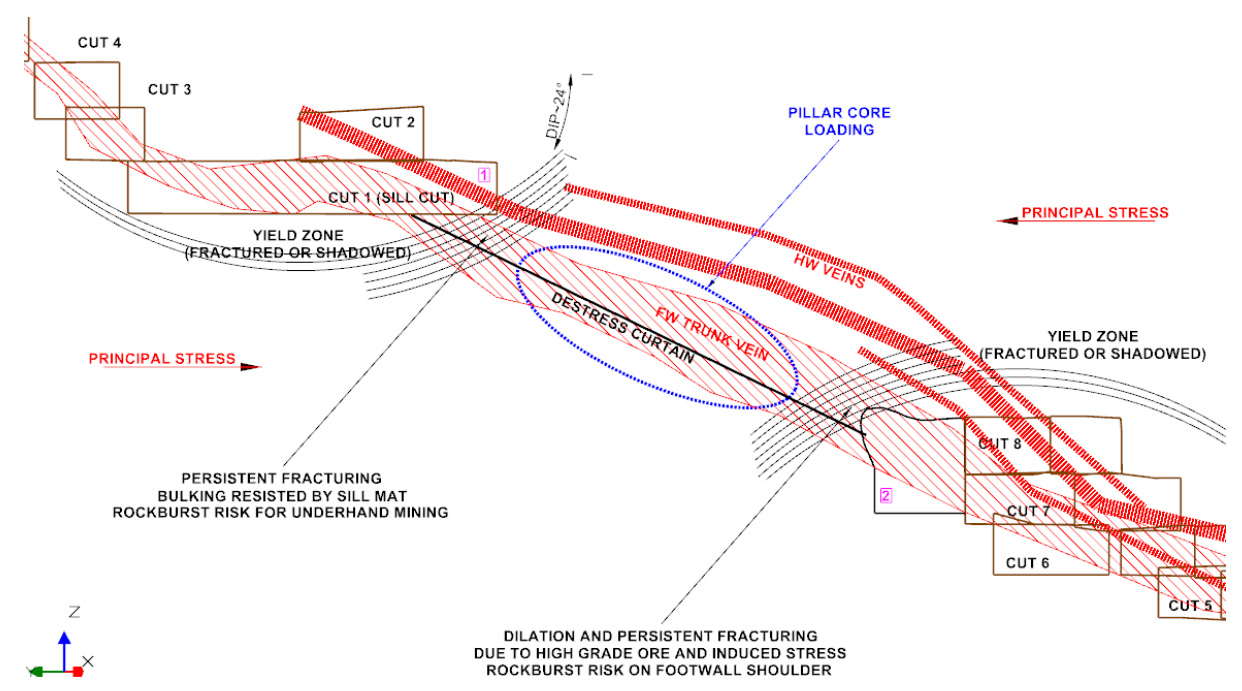

Figure 10 Section view (not to scale) of a typical flat lying sill pillar encountered in 153 Orebody. Sketch to show interpreted failure mechanism observed while mining. Sill loading, local rock fracturing/bulking and yield zones are shown 

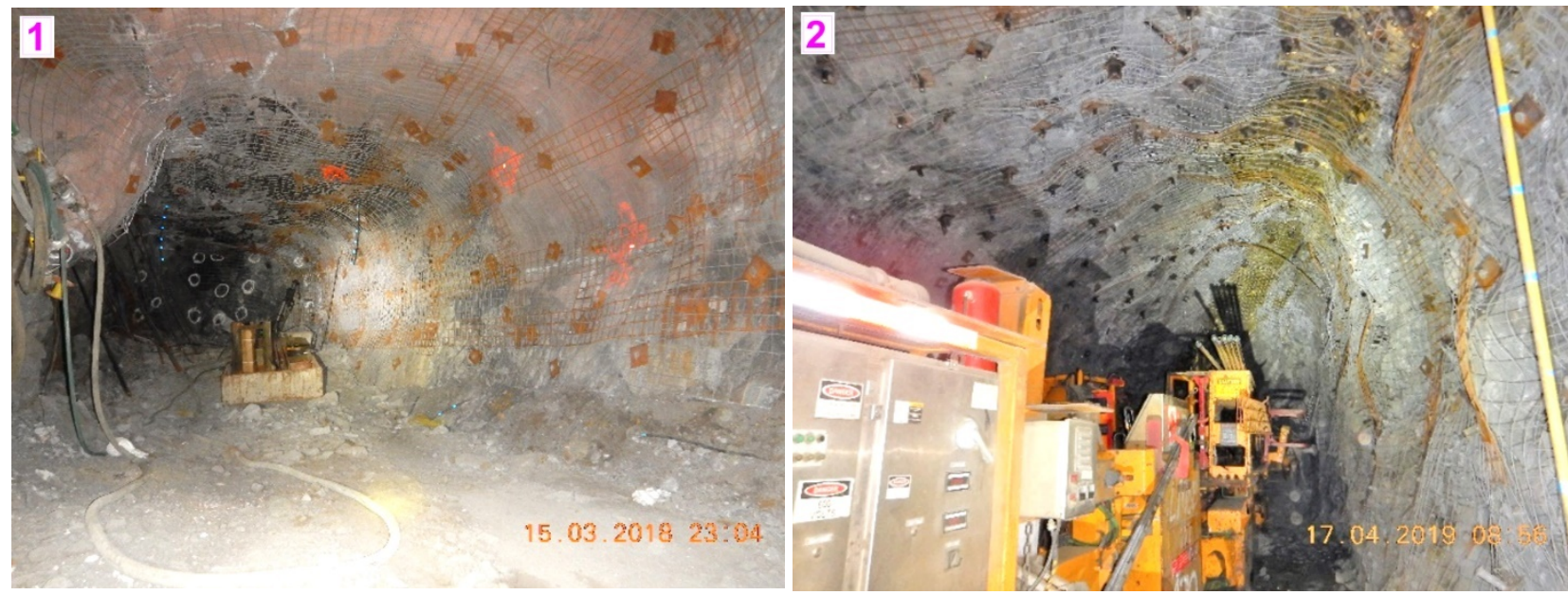

Figure 11 Underground photos corresponding to Figure 10 labels. (1 left) under-cut-and-fill heading with dynamic support (cross-straps) installed on potentially high stress right wall. Pink shotcrete is a fast-setting/high strength blend; (2 right) overhand cut-and-fill heading showing ground conditions and support installed on potentially high stress back and right wall $(2.4 \mathrm{~m} / 3.5 \mathrm{~m}$ yielding inflatables)

In high stress sill pillars, the primary support system employed consists of $2.4 \mathrm{~m}$ yielding bolts (resin-grouted or inflatables) in the back and $2 \mathrm{~m}$ long friction stabilisers in the walls through WWM down to the floor. Domed plates and with \#0-gauge mesh squares are used to assist with bulking. A second pass of $3.6 \mathrm{~m}$ long inflatables in the back and $2.4 \mathrm{~m}$ long inflatables in the walls with \#0-gauge mesh straps is installed in-cycle prior to advancing the heading. Many variations of this support system are utilised depending on geometry and anticipated seismic response. The variation includes location of the second pass support (back/walls, both) and density of straps (single-strapping or cross-strapping - Figure 12).
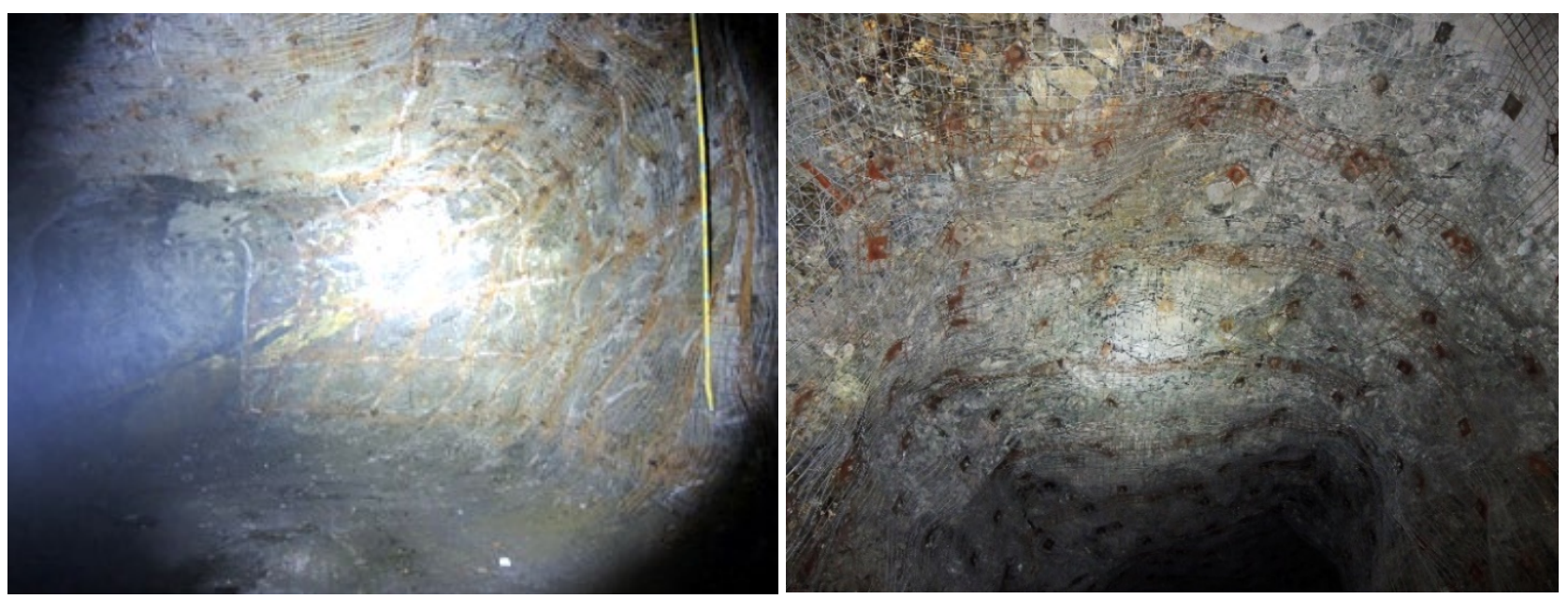

Figure 12 (a) Typical high stress support system being utilised in sill pillars; (b) Dilation/bulking and support system performance in a seismically active sill pillar. Support in both images include variations 2.4 and $3.6 \mathrm{~m}$ yielding inflatables in the back and walls with \#0-gauge mesh straps

The support system specified above has been selected for entry in high stress sills. Operational ease is also considered and generally, inflatable bolts are selected in short-term areas versus resin-grouted support. The decision lies in a safer installation, resulting in less operator exposure to the 'to-be-supported' round and less hole oversizing concerns in high-grade ore. Field observations have proven that in dynamic conditions (when spans are minimised) the support system is highly effective (Figure 12). 


\section{$3 \quad$ Mine pillars: case histories}

The following case histories show how ground support systems have performed in high stress areas.

\subsection{Local pillar}

As discussed, local pillars are sometimes created in the early cuts as veins are defined. As subsequence cuts are mined, and rib pillars become slender, they can be prone to strainbursts. An example of this can be seen in Figure 13; a narrow vein heading was a-seismic until a local pillar was created and generated an increase in seismicity (a strainburst occurred from unsupported ground).

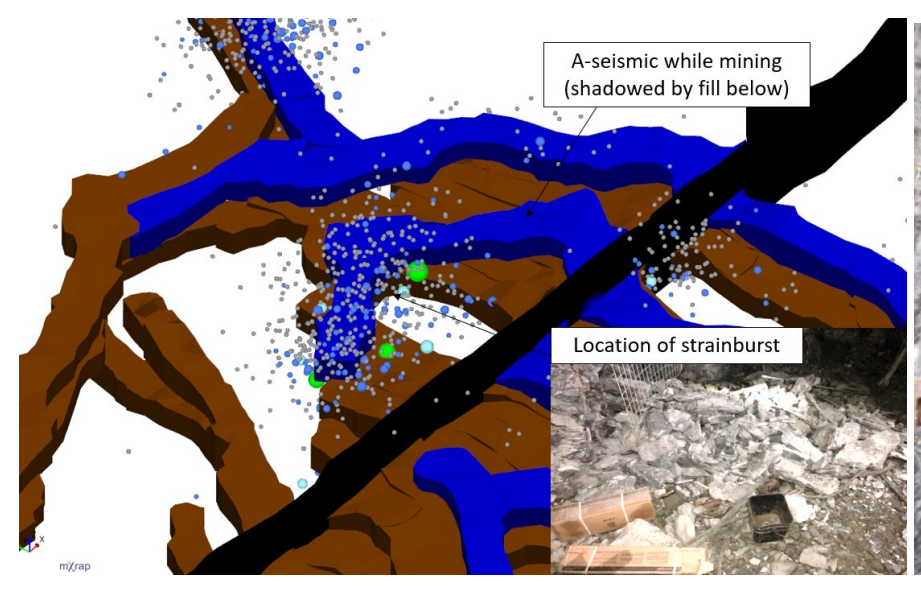

(a)

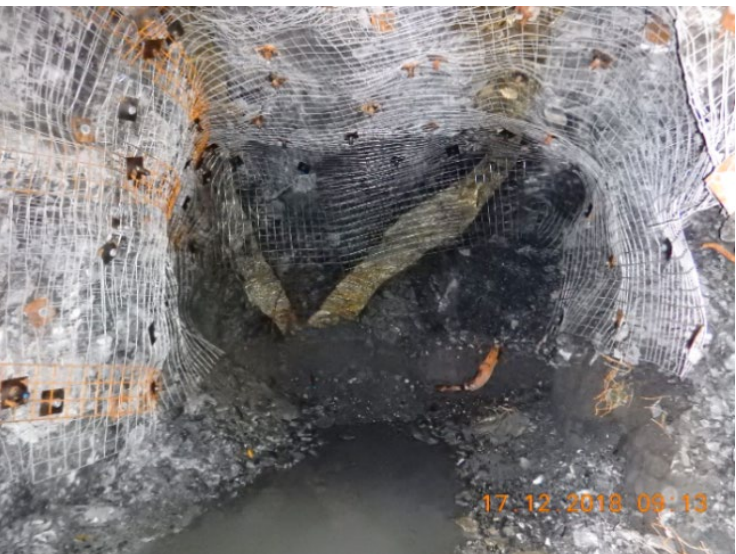

(b)

Figure 13 (a) Isometric view of 170-5700-P1 showing seismicity generated while mining by a local rock pillar. Image highlights how the heading was a-seismic while on top of the filled region and became active once the rock pillar was reached; (b) Ground support utilised consists of $1.8 \mathrm{~m}$ yielding inflatables and strapping installed over $1.8 \mathrm{~m}$ split set bolts and welded wire mesh. Sandfill can be seen in the face and right wall and is a sign of a stress shadowed area

Local pillar seismicity is primarily geometry driven and is managed through worker awareness, design/sequencing, ground support and local drift de-stressing. Camera surveyed observation holes are commonly used for design justification in areas where local high stress is anticipated. Figure 13 also shows the ground support installed; fit for purpose where the high stress wall is reinforced with \#0-gauge mesh straps and $1.8 \mathrm{~m}$ dynamic bolts; all installed with the Fletcher boom-bolter.

\subsection{Regional pillar}

The $\mathrm{T} 1 / \mathrm{T} 3$ is the bottom-most sill in the $\mathrm{MOB}$ and the ore is divided by a central waste pillar (Figure 14). Six cuts were mined on the T3 side and five cuts were mined on the T1 side. Cuts were mined overhand PPCF and the remaining sill is being mined as open stopes retreating away from the central waste pillar. To facilitate early ore from the T3 stoping front, an internal (temporary) ore access was driven through the high stress waste pillar (since the permanent access was required from the east abutment). The access was driven in high stress ground and a significant package of support elements was installed. The support system included resin-grouted yielding bolts with \#0-gauge mesh strapping, over shotcrete and a pattern of $5.5 \mathrm{~m}$ twin cables. 

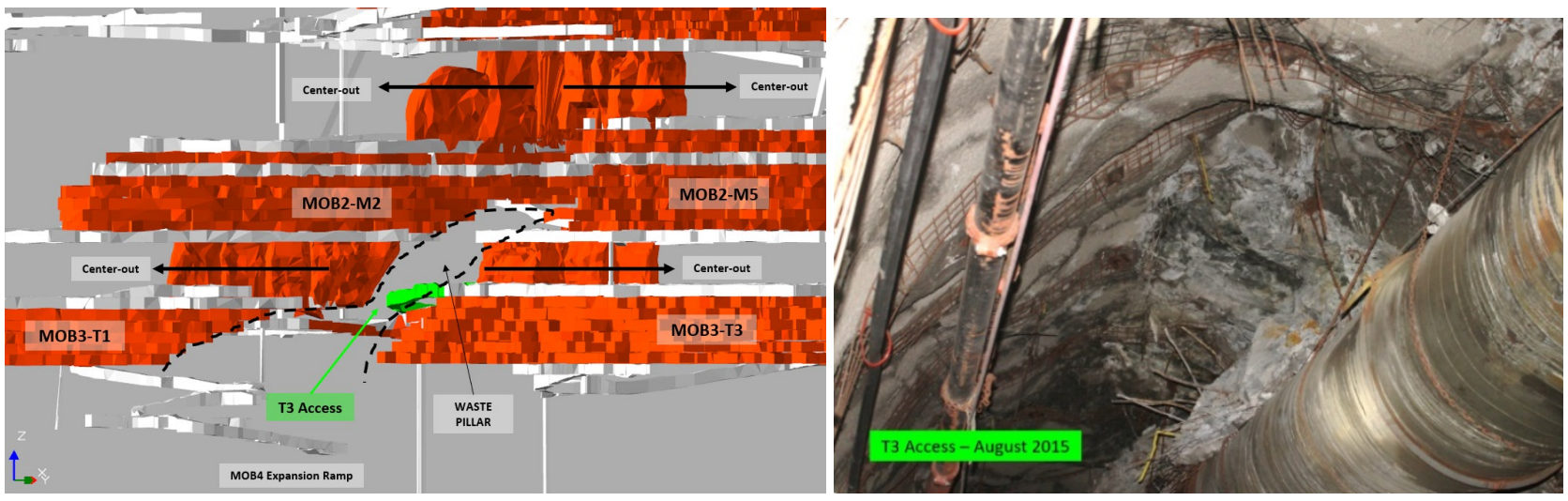

Figure 14 (a) long section looking north (not to scale) showing the T1/T3 mining front and the regional waste pillar. Temporary T3 access shown in green; (b) underground photo showing rockburst damage in the T3 access following a large seismic event

The first open stope of the centre-out sequence generated a significant seismic response in the waste pillar. The largest seismic event was 3.5 Nutli magnitude (Geological Survey of Canada), which occurred greater than 48 hours after the final stope crown blast. The internal T3 access sustained damage due to the seismicity. It can be seen in Figure 14 that the damage consisted of ejection of fractured rock near the surface of the excavations. Due to the rockburst, it was decided to abandon the T3 access. This example shows how in many cases, ground support has a difficult time accommodating seismic loading in high stress pillars and justifies the need for a deeper embedment of yielding support (i.e. $>3 \mathrm{~m}$ ), as well as, a more robust surface support (plating cables and cross-strapping). In general, conservative mine design/planning is always a better approach.

\subsection{Flat lying sill pillar}

The 5080 level sill pillar is in the bottom of the 153 Orebody with an average ore dip of 18 degrees. Six narrow vein $2.7 \mathrm{~m}$ high cuts were mined, bringing the sill to a height of $10 \mathrm{~m}$ (width:height $\sim 1.0$ ). Based on geometry and seismic history, the mine treated the sill as high stress and after cut six, a large-scale sill de-stressing program was proactively completed (Townend \& Sampson-Forsythe 2014). The mine did not have confidence in sill recovery using bulk mining in a shallow dipping and highly variable geometry. Cut seven was designed larger (4.5 $\mathrm{m}$ drifts - sacrificing dilution) and the cut was sequenced hanging wall to footwall avoiding the high stress pillar core. The plan was to move to cut eight (abutment veins) and the core would be mined later when it was stress shadowed. Figure 15 shows the general mining geometry of the 5080 sill.

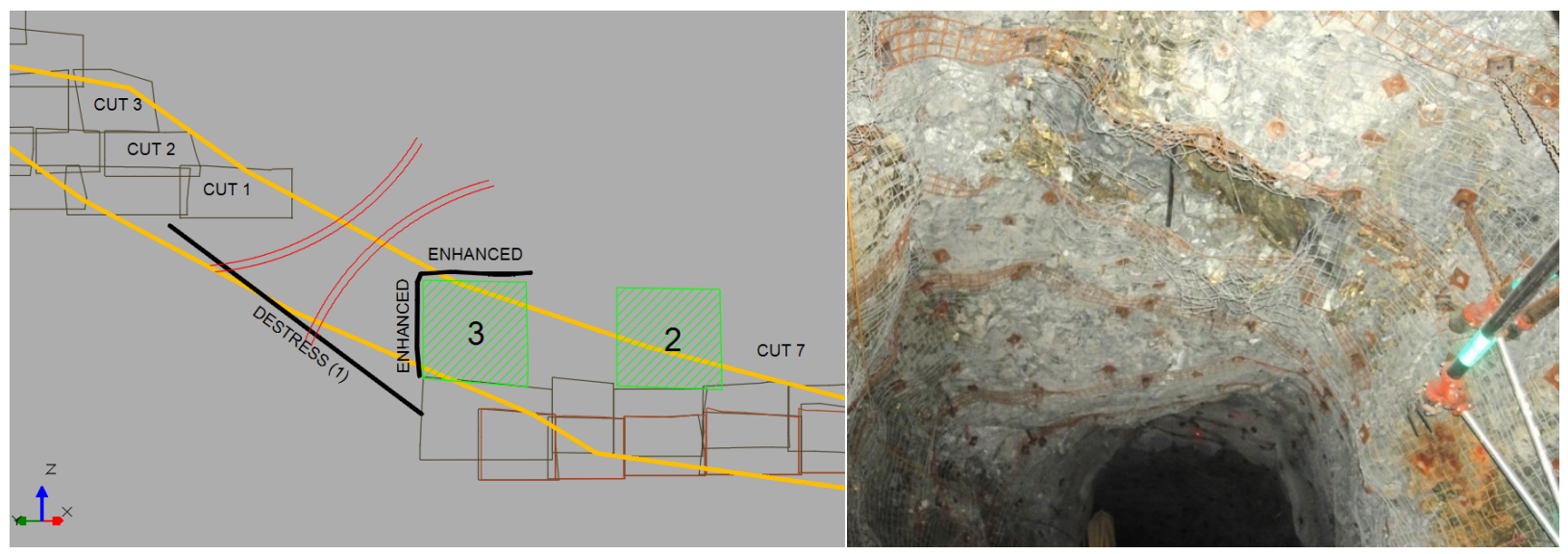

Figure 15 (a) Section looking west (not to scale) showing 153-5080 sill pillar and associated mining geometry; (b) Dilation/bulking and support system performance in 5080 sill pillar following a magnitude 2.2 seismic event. Support includes 3.6 and $2.4 \mathrm{~m}$ yielding inflatables in the back and walls respectively with \#0-gauge mesh strapping, over $2.4 \mathrm{~m}$ resin-grouted rebar 
The high stress heading ' 3 ' shown in Figure 15 was supported as discussed (first pass $2.8 \mathrm{~m}$ yielding bolts, strapped $3.6 \mathrm{~m}$ yielding inflatables). During early mining on cut seven, a 2.2 Nutli magnitude (Geological Survey of Canada) seismic event occurred in the sill pillar followed by a series of small magnitude events. No workers were in the area at the time of the event since it occurred after a development blast and the block was under a seismic stand-off. Although the ground support in some areas was compromised and needed rehabilitation, it performed well by retaining the bulked and fractured material during the large event (Figure 15).

\section{Conclusion}

As discussed in this paper, by Yao et al. (2014) and Townend \& Sampson-Forsythe (2014), many strategies have been employed to manage the challenging ground conditions at Coleman. At the forefront, is understanding rock mass failure mechanisms using seismic monitoring and regular underground observations.

In addition, Coleman has been challenged since the mine plan required sill pillars to sustain production and in many cases, sills are recovered using non-entry mining methods (i.e. bulk stoping). However, it is sometimes required to enter high stress areas due to mining geometry and ore characteristics and in these cases, ground support and equipment mechanisation play important roles.

\section{Acknowledgement}

The authors thank Vale Canada for permission of publish. Thank you to the many employees of Coleman mine and the Vale North Atlantic Rock Engineering team for the frequent discussions regarding ground control strategies.

\section{References}

Itasca Consulting Canada Inc. 2017, 153 Orebody FLAC3D Numerical Modelling, internal report, unpublished.

Langevin, FM \& Wilson, D 2013, 'Lapa Mine - ground control practices in extreme squeezing ground', in Y Potvin \& B Brady (eds), Proceedings of the Seventh International Seminar on Ground Support in Mining and Underground Construction, Australian Centre for Geomechanics, Perth, pp. 119-131.

Lightfoot, P 2017, Nickel Sulphide Ores and Impact Melts: Origin of the Sudbury Igneous Complex, Elsevier.

Simser, BP 2006, 'Strategic and tactical approaches for mining at depth at Falconbridge's Craig Mine', in J Hadjigeorgiou \& M Grenon (eds), Proceedings of the Third International Seminar on Deep and High Stress Mining, Australian Centre for Geomechanics, Perth, $14 \mathrm{p}$.

Townend, S \& Sampson-Forsythe, A 2014, 'Mitigation strategies for mining in high stress sill pillars at Coleman Mine - a case study', in M Hudyma \& Y Potvin (eds), Proceedings of the Seventh International Conference on Deep and High Stress Mining, Australian Centre for Geomechanics, Perth, pp. 65-77.

Yao, M, Sampson-Forsythe, A \& Punkkinen, AR 2014, 'Examples of ground support practice in challenging ground conditions at Vale's deep operations in Sudbury', in M Hudyma \& Y Potvin (eds), Proceedings of the Seventh International Conference on Deep and High Stress Mining, Australian Centre for Geomechanics, Perth, pp. 291-304. 
